\title{
Diagnóstico da condição crônica da criança: situações de vulnerabilidade vivenciadas pelos familiares/cuidadores
}

\author{
Diagnosis of the child's chronic condition: situations of vulnerability experienced by Family \\ members/caregivers
}

Diagnóstico de la condición crónica del niño: situaciones de vulnerabilidad vividas por familiares/cuidadores

\section{Resumo}

Objetivo: Conhecer as situações de vulnerabilidade vivenciadas pelos familiares/cuidadores na recepção do diagnóstico da condição crônica da criança. Metodologia: Trata-se de uma pesquisa descritiva exploratória com abordagem qualitativa da qual participaram 10 familiares/cuidadores de crianças com condição crônica, que estiveram hospitalizadas em unidades pediátricas de um município ao Sul do Brasil. As informações foram coletadas por meio de entrevista e analisadas a partir da Análise Temática. A pesquisa foi aprovada pelo Comitê de Ética em Pesquisa na Plataforma Brasil. Resultados: Identificou-se a presença da vulnerabilidade ontológica, ética, social e cultural. Desvelaram-se sentimentos como sofrimento, choque e angústia relacionados ao diagnóstico da condição crônica que impôs várias dificuldades a serem enfrentadas pelos familiares/cuidadores. Conclusão: Identificou-se que com o diagnóstico da condição crônica da criança ocorrem diversas mudanças nos hábitos dos familiares/cuidadores, necessitando muitas vezes que a família reorganize toda a sua estrutura, desde a alimentação até suas atividades externas, como trabalho e socialização.

Palavras-chave: Criança; Doença crônica; Família; Diagnóstico; Cuidadores.

\begin{abstract}
Objective: To know the situations of vulnerability experienced by family members/caregivers when receiving the diagnosis of the child's chronic condition. Methodology: This is exploratory descriptive research with a qualitative approach in which 10 family members/caregivers of children with chronic conditions who were hospitalized in pediatric units in a city in southern Brazil participated. Information was collected through interviews and analyzed using the Thematic Analysis. The research was approved by the Research Ethics Committee at Plataforma Brazil. Results: The presence of ontological, ethical, social and cultural vulnerability was identified. Feelings such as suffering, shock and anguish related to the diagnosis of the chronic condition were revealed, which imposed several difficulties to be faced by family members/caregivers. Conclusion: It was identified that with the diagnosis of the child's chronic condition, several changes occur in the habits of family members/caregivers, often requiring the family to reorganize its entire structure, from food to its external activities, such as work and socialization.
\end{abstract}

Keywords: Child; Chronic disease; Family; Diagnosis; Caregivers. 


\begin{abstract}
Resumen
Objetivo: Conocer las situaciones de vulnerabilidad que viven los familiares/cuidadores al recibir el diagnóstico de la condición crónica del niño. Metodología: Se trata de una investigación descriptiva exploratoria con abordaje cualitativo en la que participaron 10 familiares/cuidadores de niños con enfermedades crónicas que fueron hospitalizados en unidades pediátricas de una ciudad del sur de Brasil. La información se recopiló a través de entrevistas y se analizó mediante el análisis temático. La investigación fue aprobada por el Comité de Ética en Investigación de Plataforma Brasil. Resultados: Se identificó la presencia de vulnerabilidad ontológica, ética, social y cultural. Se revelaron sentimientos como sufrimiento, conmoción y angustia relacionados con el diagnóstico de la condición crónica, que impuso varias dificultades a ser enfrentadas por familiares/cuidadores. Conclusión: Se identificó que, con el diagnóstico de la condición crónica del niño, ocurren varios cambios en los hábitos de los familiares/cuidadores, requiriendo muchas veces que la familia reorganice toda su estructura, desde la alimentación hasta sus actividades externas, como el trabajo y la socialización.
\end{abstract}

Palabras clave: Niño; Enfermedad crónica; Familia; Diagnóstico; Cuidadores.

\title{
1. Introdução
}

O diagnóstico da condição crônica na infância ocasiona, nas famílias, surpresa e abalo emocional, por ser algo novo, desconhecido e diferente, passam a conviver com incertezas, principalmente quando a família desconhece casos de crianças com condição crônica (Xavier, Gomes \& Cezar-Vaz, 2020). Quer a criança tenha nascido com a doença, quer a condição crônica tenha se desenvolvido ao longo da infância, os pais deparam-se com uma realidade na qual suas expectativas e planos precisarão ser ajustados, devido à condição e às limitações que a criança apresenta (Pimenta et al., 2020).

Quando diagnosticada com uma condição crônica a pessoa sente danos físicos e emocionais em virtude das transformações que ocorrem na sua vida diária e no seu corpo. Para a criança tudo isso é mais intenso, pois ela ainda está se desenvolvendo e se construindo, o modo como ela irá se comportar diante da nova situação é distinto daquele dos adultos, já que a criança possui uma forma única de se colocar no mundo (Frota et al., 2017).

A condição crônica é compreendida como uma situação de difícil aceitação para as famílias, visto que a preocupação dos pais se focaliza no desenvolvimento saudável e no crescimento dentro dos padrões esperados para seus filhos, portanto a doença implica em limitações e mudanças no estilo de vida de toda família (Cardoso et al., 2021). O medo da possibilidade da perda do filho é assustador, sendo esse sentimento inevitável e, muitas vezes, estagnante. Além do medo da perda é possível que a pessoa se sinta completamente desamparada por aqueles que acercam, mesmo que de fato isso não ocorra (Pimentel, Targa \& Scardoelli, 2017).

Na ocorrência da condição crônica as famílias, em especial as mães, percebem a vulnerabilidade existencial do filho, passam a percebê-lo como um ser humano finito (Roselló, 2009). Ao identificarem a possibilidade da sua finitude, a angústia e a preocupação podem interromper a esperança, para com o futuro, de forma que a mãe desenvolva dificuldade para se adaptar a situação de conviver com a complexidade do existir com uma condição crônica (Freitag, Milbrath \& Motta, 2016). Levandoa um estado de sofrimento que é considerado filosoficamente a expressão máxima da vulnerabilidade humana (Roselló, 2009).

O existir no mundo com uma condição crônica traz consigo um prognóstico incerto, marcado por incapacidades, prejuízos nas habilidades inerentes da infância como correr, brincar e crescer. Dessa forma, conhecer as situações de vulnerabilidades da criança com condição crônica e de sua família para assim ter elaboração de estratégias de cuidado capazes de minimizar a vulnerabilidade social e cultural dessas crianças e famílias auxiliando-as no exercício de autonomia (Dominguez \& Castro, 2015).

Considerando que existe uma fragmentação na atenção à saúde de crianças com condição crônica e lacunas assistenciais (Wolkers et al., 2019) que podem estar vinculadas à falta de conhecimento acerca das vulnerabilidades experienciadas pelas famílias e por essas crianças, torna-se relevante conhecer as situações vivenciadas por elas. Para contribuir com a discussão acerca dessa temática, estabeleceu-se a seguinte questão de pesquisa: quais são as situações de vulnerabilidade vivenciada pelos familiares/cuidadores ao receberem o diagnóstico da condição crônica da criança? 
Portanto, o objetivo do presente estudo é conhecer as situações de vulnerabilidade vivenciadas pelos familiares/cuidadores na recepção do diagnóstico da condição crônica da criança.

\section{Metodologia}

Trata-se de uma pesquisa descritiva exploratória com abordagem qualitativa, realizada no período de junho a agosto de 2018. Foram respeitados os preceitos éticos determinados pela Resolução n ${ }^{\circ} 66 / 12$ (Brasil, 2012) do Conselho Nacional de Saúde do Ministério da Saúde. A coleta das informações teve início após a aprovação do projeto de pesquisa pelo Comitê de Ética em Pesquisa (CEP) sob nº 2.736.019 na Plataforma Brasil. A pesquisa foi conduzida e estruturada com referência nos Critérios de Consolidação para Relatórios de Pesquisa Qualitativa (COREQ) (Tong, Sainsbury \& Craig, 2007).

O anonimato dos entrevistados foi respeitado sendo eles identificados pelo codinome "FM", "FP", "FVó" ou "FVô", respectivamente para Familiar Mãe, Familiar Pai, Familiar avó ou Familiar avô, seguido por número crescente que se refere à ordem das entrevistas.

O referencial teórico que sustentou este estudo foi o da vulnerabilidade, relacionada à fragilidade e precariedade do ser humano, que é essencialmente vulnerável a condições climáticas, a enfermidades e ao sofrimento (Roselló, 2009). De acordo com esse referencial (Roselló, 2009) pode-se distinguir cinco tipos de vulnerabilidade: ontológica (na constituição do ser que é limitado, dependente e determinado por sua finitude); ética (relaciona-se ao dever moral de proteger os indivíduos mais frágeis); social (possibilidade do ser humano ser objeto de violência no meio social); natural (entorno ambiental repercute sobre a vida do ser humano e vice-versa), e cultural (a ignorância, desconhecimento acerca das diferentes ordens de saber, tronando o indivíduo manipulável e desprotegido do abuso de poder de outrem).

Considerando que a doença leva a alterações na vida do indivíduo relacionadas à sua estrutura somática e também a sua integridade (Roselló, 2009). Nesse sentido, a vivência da condição crônica da criança traz para ela e para a sua família exposição a diversas situações de vulnerabilidade.

A coleta das informações ocorreu no domicílio, no trabalho e em serviços de saúde, em munícipios localizados na região sul do Rio Grande do Sul, onde os participantes residem ou buscam assistência à saúde.

Participaram 10 pessoas, não sendo necessário a inserção de mais, pois ocorreu a saturação das informações (Hennink, Kaiser \& Marconi, 2017). A seleção dos participantes ocorreu de forma intencional a partir do banco de informações do Projeto de Pesquisa Vulnerabilidades da criança e adolescente com doença crônica: cuidado em rede de atenção à saúde.

Como critérios de inclusão foram respeitados: ser familiar/cuidador da criança com idade entre quatro e 12 anos com condição crônica; estar cognitivamente apto a participar da pesquisa. Foram excluídos os familiares/cuidadores de crianças em cuidados paliativos ou em situações críticas de vida e os familiares/cuidadores menores de 18 anos.

A coleta das informações ocorreu por meio de observação simples, entrevista semiestruturada e o diário de campo para o registro das observações/percepções da pesquisadora. A entrevista semiestruturada conteve questões abertas e fechadas sobre a caracterização dos participantes e as vivências experienciadas no diagnóstico da condição crônica na criança.

O diário de campo continha notas de campo, com os detalhes da observação; notas teóricas relacionadas às percepções relativas à compreensão da pesquisadora e notas metodológicas que se refere à análise do conteúdo das notas de campo. Foram feitas notas de campo, registradas ao final de cada encontro, contendo informações colhidas, observações, percepções e sentimentos.

As entrevistas foram realizadas pela pesquisadora do estudo em horários previamente agendados com os participantes da pesquisa, sendo o primeiro contato por meio de telefonemas. As entrevistas foram individuais, com duração de aproximadamente 40 minutos. Utilizou-se o gravador de voz para o registro dos depoimentos, que posteriormente foram transcritos na íntegra. 
Para a interpretação dos dados, utilizou-se a análise temática que se constitui em um método para identificar, analisar e relatar padrões (temas), organizar e descrever todo o conjunto de dados em detalhes, além de interpretar aspectos do tema de pesquisa. Para tanto, seguiu-se seis fases: familiarização com os dados por meio da transcrição, leitura e releitura; geração dos códigos iniciais; agrupamento dos temas, gerando nomes e definições com base nos dados mais relevantes de acordo com a questão norteadora; verificação dos temas conforme os extratos codificados; atribuição dos nomes dos temas; síntese dos resultados (Braun \& Clarke, 2019).

\section{Resultados}

Participaram do estudo 10 famliares/cuidadores das crianças com condição crônica, sendo eles sete mães, um pai e dois avós. As idades desses variou de 27 a 58 anos, com escolaridade de ensino fundamental incompleto (6/10), ensino médio completo (3/10) e ensino superior completo (1/10). A renda dos participantes estava entre $R \$ 290,00$ e $R \$ 2.000,00$. Tendo como ocupação ser do lar (5/10), desempregados (2/10), contadora (1/10), domador de equinos (1/10), agricultura (1/10). Em relação ao estado civil tinha casados (7/10) e solteiros (3/10).

Os resultados revelaram como foi para a família receber o diagnóstico da condição crônica na criança, os sentimentos que emergiram a partir da notícia e as dificuldades enfrentadas pelos familiares/cuidadores. Neste estudo identificou-se a presença de quatro dessas vulnerabilidades: ontológica, ética, social e cultural. Esses foram organizados em dois temas: a) Sentimentos emergidos ao receber o diagnóstico da condição crônica da criança; e b) Dificuldades enfrentadas ao receber o diagnóstico da condição crônica da criança.

\section{Sentimentos emergidos ao receber o diagnóstico da condição crônica da criança}

Ao dialogar com os participantes sobre a recepção do diagnóstico da condição crônica identificou-se que a maioria recebeu a notícia durante a hospitalização da criança. Muitos participantes relataram sobre a demora do diagnóstico o que progrediu para a piora do estado de saúde da criança:

“Ele ficou um tempo assim, ficou uns 10 dias quando ele estava internado até ter o diagnóstico[...]" (FM4).

"Até o dia 19 de junho ela não tinha nada, ela fez exames poucos dias antes e não deu nada [...]. Ela internou e [...] foi direto para a UTI. [...] aí eles não descobriam o que é que ela tinha (diagnóstico de Diabetes Mellitus)" (FM6).

"A gente chegou ao Pronto Socorro, e a gente não sabia o que era. Aí a doutora dizia que era isso, era aquilo" (FVó1).

Os relatos das mães mostram a demora em ter um diagnóstico específico e em iniciar o tratamento adequado para a criança, o que acarretou sofrimento, angústia e dor.

Fazia tempo que ele vinha doente [...] tendo umas dores de barriga, uns vômitos e diarréia. Só que então aqui [...] [nome da cidade] as pessoas estavam tratando ele para intolerância à lactose [...] mandaram eu cortar tudo, todos os alimentos dele, que tem leite e tudo. [...] aquilo foi se agravando cada vez mais, foi piorando [...] e eu fazia os exames nele e não dava nada. [...] quando ele teve uma crise forte [...] diarréia forte [...] e vômitos, levei ele para a Santa Casa [...]. Achavam que ele estava com hepatite, porque ele urinou preto, tipo uma coca-cola. Levaram ele para o isolamento [...] eles não estavam chegando à conclusão nenhuma (FM5).

"Eu não sabia direito o que era. Então, eu fiquei bastante chocada, porque é uma criança” (FM4).

Ao receberem a notícia de que a criança possui uma condição crônica os pais passaram por um período de choque e de sentimentos diversos em relação ao desconhecido, aos sinais e sintomas apresentados pela criança, ao medo de perder o filho: 
"Foi um susto. Eu já conhecia (a patologia) mais ou menos, mas nunca tinha participado, assim, pessoalmente. Mas, fiquei muito assustada” (FM3).

"Ai eu fiquei assim, um pouco em choque [...] me deu um apagão" (FM6).

“Foi péssimo. Quando me deram a notícia eu fiquei abalado” (FP1).

“Foi ruim, porque no começo a gente pensou mil e uma coisas” (FVó1).

“Eu fiquei com medo, sinceramente eu fiquei com medo de perder ele” (FM5).

Porém, mesmo sendo caracterizado como um período de choque para as famílias, com o passar do tempo o processo de aceitação foi sendo facilitado, FM7 confirma isso no seu depoimento:

"Foi difícil, foi um choque. Eu entrei em pânico [...]. Foi difícil, a ficha só caiu depois [...] foi caindo devagarzinho” (FM7).

\section{Dificuldades enfrentadas ao receber o diagnóstico da condição crônica da criança}

As dificuldades enfrentadas para o recebimento do diagnóstico foram destacadas pelos familiares/cuidadores que residiam em outros municípios e possuíam limitado acesso aos serviços de saúde. Os familiares/cuidadores relataram que apenas quando foram para a cidade de Pelotas (município referência para região) tiveram o diagnóstico correto e puderam iniciar o tratamento adequado:

"[...] me mandaram para Pelotas" (FM3).

A doutora que atendeu ele, disse: mãe eu vou mandar teu filho agora para Pelotas, porque aqui [...] [nome do município] não tem mais o que fazer por ele, foi quando a gente foi para Pelotas, para o Pronto Socorro [...] começou a fazer exames [...] conheci o doutor, que foi quem operou ele (FM5).

A ausência do profissional pediatra também surgiu nas falas das famílias, sendo considerado como limitante no serviço de saúde. Conforme o depoimento que segue o clínico que atendeu a criança orientou a mãe a procurar um pediatra:

"Aqui [...] [cidade em que residem] tem internação pediátrica, só que aqui o doutor que me atendeu ele não falou coisa com coisa, porque ele só disse: se tu puder tu leva no pediatra, mas não me falou que o rim dele não estava funcionando" (FM4).

Observou-se que, muitas vezes, por não terem as respostas necessárias as famílias peregrinam com idas e vindas aos serviços de saúde.

“E ia para o PS, do PS ia para a Santa Casa, da Santa Casa ia para a FAU” (FM2).

A primeira vez que ele passou mal eu tive que levar no hospital, porque o posto de saúde estava em greve aqui. Aí levei no hospital [...], aí no outro dia eu paguei uma consulta particular com o pediatra [...]. A doutora particular [...] que me falou que os rins dele estavam parados, que não estavam funcionando (FM4).

“A gente tem o sindicato rural, a médica examinou ela e disse que era infecção respiratória. [...] aí, a gente chegou em casa com ela e a guria começou a vomitar e começou a ficar toda roxa, aí a gente teve que sair com ela correndo para o PS" (FM6).

Outro ponto de destaque nos depoimentos foi que, em alguns casos, as famílias iniciam o tratamento para a condição crônica da criança, mas ainda não aceitam o diagnóstico, esperando pela cura. Isso pode ser observado na fala de FM6, cuja filha recebeu o diagnóstico de esquizofrenia: 
Mas quando ele (médico) falou em esquizofrenia, Bah! Olha, eu ainda tenho esperança que não seja. Ela enxerga bichos, ela enxerga pessoas [...]. Ela se machuca. Primeiro ela não sabe o que ela faz ou o que ela estava fazendo. Ela faz uma ferida e daquela ferida ela começa coçar [...] e incha [...]. Aí nós começamos a fazer tudo que é exame nela, de alergia e de tudo [...]. Levava no doutor, levava no posto. Ai diziam 'ah é um bicho venenoso' [...]. A pediatra dela começou a fazer uns exames [...] e nada, ela não tinha alergia a nenhum daqueles bichos. Aí nesse dia, que ela se machucou na testa, eu estava sentada no sofá, e de olho [...]. Ela simplesmente foi assim para o lado do pilar [...] e deu com a cabeça. [...] nesse dia eu vi, aí que eu acreditei. Porque é difícil para uma mãe, que cuida [...] (FM6).

O processo para a aceitação do diagnóstico e dos cuidados que o acompanham é temido pela família e o desconhecimento acerca da patologia torna-se um fator agravante no momento do recebimento da notícia.

"Eu não conhecia essa doença. [...] e aquilo era totalmente desconhecido. [...] saber que tem uma doença, sem saber se aquilo ali vai ter melhora ou se não vai ter melhora. Passa de tudo pela cabeça da gente” (FM5).

"Porque era uma coisa assim, que eu nem sabia. Quando ela falou assim cetoacidose, eu nunca tinha nem ouvido falar nessa palavra. Aí, eu levei dois dias procurando na internet uma palavra parecida” (FM6).

"Eu não achei que era uma coisa assim, eu achei que fosse uma coisinha simples. Que ela fosse fazer um tratamento e fosse ficar boa" (FM7).

A situação do desconhecimento acerca da patologia gera angústia nas famílias, inclusive se autoinflingindo culpabilidade e impotência, demonstrando o impacto do recebimento da notícia e o sofrimento dos familiares/cuidadores.

“Será que eu estou fazendo o máximo que eu posso?” (FM1).

"Talvez não tivesse chegado nesse ponto, se eu tivesse procurado um médico fora daqui, mas a gente não sabe" (FM5).

“Eu perguntei para ela (médica), 'mas a culpa é minha? Eu fiz alguma coisa?' Ela disse 'não, ela nasceu assim'., (FM6).

Quando eu vi ela com oxigênio no hospital, eu vi que não podia fazer nada, que tinha que deixar ela ali. [...] e não saber se estão fazendo o certo, porque a gente vê tanta coisa na TV, será que isso é o máximo que eles podem estar fazendo? Ou eu podia estar fazendo outra coisa? Correr atrás de outra ajuda (FM1).

"Era péssimo, porque eu nunca tive um caso desses na família" (FP1).

“A gente não sabia o porquê? ou de quem?” (FVó1).

Apesar de todo transtorno que a condição crônica traz para a criança e sua família, alguns participantes relataram o grande sofrimento até obterem o diagnóstico, esse era tamanho que ao receber o diagnóstico, mesmo que de condição crônica, houve certo alívio.

"Mas para mim foi melhor descobrir logo o que ele tinha, do que ficar aqui, tomando e tomando remédio, sem saber, e cada vez se agravando mais" (FM5).

\section{Discussão}

As famílias descreveram o choque inicial sentido quando receberam o diagnóstico da condição crônica na criança, percebendo sua vulnerabilidade de existir como ser humano (Roselló, 2009), sujeito as facticidades existenciais, a situações incontroláveis pelo ser, que explicita a vulnerabilidade ontológica. A descoberta de que o filho tem uma doença, que o acompanhará por toda a vida gera, inicialmente, nos pais, um período de choque, seguido por tristeza ou ansiedade, para depois, gradualmente, ocorrer à aceitação da condição da criança (Milbrath et al., 2016). É necessário salientar que em alguns 
casos essa aceitação não acontece, como por exemplo, no caso do familiar/cuidador que refere não acreditar no diagnóstico de esquizofrenia da criança.

Nesse período inicial, tem-se também a presença do choro, da manifestação de sentimentos de desamparo e de ânsia por fugir. Logo após, vem o equilíbrio caracterizado pela aceitação de que a condição existe e, por último, a reorganização familiar (Xavier, Gomes \& Cezar-Vaz, 2020). Cabe salientar que mesmo que a família em alguns momentos negue a condição da criança, como no depoimento da FM6, que refere ainda ter "esperança que não seja esquizofrenia" ela busca se (re)organizar para cuidar da criança.

$\mathrm{O}$ adoecimento de um filho pode fazer com que a família perceba o auge da vulnerabilidade que há em existir como ser humano, um ser vulnerável cuja única certeza é de que irá morrer (Milbrath et al., 2016). É provavelmente na doença que o ser humano consegue ter a máxima compreensão da sua vulnerabilidade, pois a doença é uma ameaça à existência do ser ${ }^{(10)}$. Quando a família percebe a vulnerabilidade da existência da criança, e compreende que apesar de sua tenra idade é um ser para a morte, ou seja, tem uma existência finita, a família vivencia uma angústia, relacionada ao medo da perda, a impotência de não ter poder sobre a condição clínica da criança, ela vive a compreensão de sua existência vulnerável e finita.

A partir dos relatos dos familiares/cuidadores, percebe-se que o diagnóstico da condição crônica da criança não foi algo rápido e fácil. A criança apresentava sinais e sintomas, porém a causa era incerta. Há também relato de tratamento incorreto, pois o diagnóstico era impreciso. Essas situações além de prolongarem os sintomas apresentados pela criança podem agravá-los, gerando assim complicações em seu estado de saúde. É importante salientar, que em alguns casos, as manifestações clínicas de uma condição crônica, inicialmente, podem ocorrer por meio de sinais e sintomas não muito específicos ou de causas diversas de doenças da infância, isso concerne em diagnósticos diversos. Além disso, o diagnóstico precoce, ao se tratar de crianças, é geralmente complicado de se obter (Frizzo et al., 2015).

Nesse momento a vulnerabilidade ontológica, se conecta a social e cultural a medida, que a facticidade existencial de vivenciar o adoecimento na infância fica mais fragilizada a medida que as crianças e seus familiares/cuidadores vão se deparando com serviços de saúde que não conseguem dar conta das suas demandas, além disso, vale ressaltar que na assistência à saúde, o paciente, nesse caso a criança com condição crônica, sofre não apenas da vulnerabilidade ontológica, ou seja, aquela que altera sua estrutura fisiológica, mas também, uma vulnerabilidade cultural, decorrente do desconhecimento dos motivos pelos quais está vivenciando essas alterações (Roselló, 2009).

Esse contexto de sofrimento, angústia e medo caracteriza-se como sendo uma situação de vulnerabilidade cultural, pois a família não sabe o que filho tem e, assim, não pode intervir em prol do seu bem-estar. Isso pode ser visto nos depoimentos que apontam a necessidade de peregrinação entre vários serviços de saúde, da realização de diversos exames e procedimentos para chegar ao diagnóstico e tratamento corretos.

Em outros relatos também se identificou a dificuldade em não conhecer a patologia, fato que interfere na aceitação do adoecimento da criança, principalmente quando trata-se de uma condição crônica. A dúvida de não saber o que o filho tem, provoca um sentimento de impotência e ansiedade na família, pois à medida que a situação previamente planejada foge do domínio dos pais e de seu conhecimento, a condição vivenciada torna-se amedrontadora. Quando se tem certeza do que ocorre, pelo menos é possível pensar sobre o acontecimento e agir a favor de (re)estabelecer o controle da situação.

Quando, inicialmente, a cronicidade da criança é desconhecida o seu diagnóstico gera medo às famílias, sendo mais difícil a aceitação da doença. O desconhecimento sobre a condição crônica da criança é caracterizado como uma situação de vulnerabilidade cultural, pois a carência de informações reflete em prejuízos emocionais, cognitivos, atitudinais e referentes às relações sociais (Collins et al., 2016; Lise et al., 2017). 
Nessa conjuntura, apesar dos familiares/cuidadores sofrerem com a hospitalização da criança e o diagnóstico da cronicidade, em determinado momento a família reconhece-se aceitando a hospitalização, por acreditar que essa é indispensável ao tratamento, e por tomar conhecimento sobre a doença (Ataide \& Ricas, 2017).

Devido às incertezas que a família possui, vive um processo de tentar achar um motivo, um culpado. Sendo difícil aceitar que existem coisas que simplesmente acontecem, não existindo, portanto, um culpado para a criança ser asmática ou diabética. Isso faz parte do existir como ser humano. É comum os pais expressarem o sentimento de culpa devido à doença da criança, pois possuem uma preocupação de que foram eles mesmos os causadores do problema, analisando os atos passados ou presentes (Brotto \& Guimarães, 2017).

Com a confirmação do diagnóstico os pais sentem alívio e tristeza ao mesmo tempo. Alívio por saberem exatamente o que se passa com a saúde do filho, e tristeza por saberem que é uma doença que os acompanhará pelo resto de suas vidas, o que explicita a sua vulnerabilidade ética, de responsabilidade por proteger essa criança que vai necessitar de cuidado ao longo de toda a sua vida. Cabe destacar que apesar da premissa de que viver humanamente significa viver na vulnerabilidade, o ser humano tem a capacidade de se compreender como um ser vulnerável e buscar meios de diminuir a sua fragilidade existencial (Freitag, Milbrath \& Motta, 2016).

Salienta-se que a desinformação e o desconhecimento das pessoas os deixam desprotegidos e fragilizados diante de qualquer abuso de poder, sendo a ignorância a máxima expressão da vulnerabilidade cultural (Brasil, 2012). Devido à falta de informação das famílias, essas desconhecem seus direitos como cidadãos o que dificulta a ação de reivindicar e tomar decisões sobre sua própria existência. Diante da falta de conhecimento, em outras palavras da vulnerabilidade cultural, as famílias podem facilmente aceitar situações e serem manipuladas, o que as deixa ainda mais vulneráveis (Brasil, 2012).

Além da vulnerabilidade cultural, as famílias ainda se deparam com o que se pode compreender como uma vulnerabilidade ética resultante de ações dos profissionais de saúde, visto que, em alguns relatos, observa-se a falta de informações da parte dos profissionais de saúde acerca do quadro clínico da criança, ampliando o desconhecimento e a vulnerabilidade das famílias. Sem informações os familiares/cuidadores buscam informações em outros locais para compreender a condição da criança. Isso posto, é fundamental que a enfermagem desenvolva habilidades para cuidar não somente da criança com condição crônica, mas também de suas famílias, compreendendo suas limitações, esclarecendo suas dúvidas, contribuindo com seus saberes e práticas, ampliando a possibilidade de atuarem no processo do cuidado e também nas decisões relacionadas a este (Favaro et al., 2020).

Foi possível evidenciar ainda a precariedade dos serviços de saúde, dos municípios em que os entrevistados residiam em relação ao estabelecimento de diagnóstico e à promoção dos cuidados necessários com a criança e sua família, configurando-se também em uma vulnerabilidade social. Esses municípios possuem apenas atendimentos locais, para casos de menor gravidade. Por outro lado, o município de Pelotas funciona como um centro de referência para os atendimentos de maior complexidade. Esse contexto dificulta a vida das pessoas que necessitam deslocar-se para centros de referência. A distância dos serviços de saúde é associada a vulnerabilidade do entorno do ser humano, seu meio ambiente, o que repercute na sua vida (Roselló, 2009).

Como limites de acesso da criança aos serviços de saúde nesses municípios, pode-se incluir o número reduzido de profissionais disponíveis para atender à comunidade. Tais limites também são observados em outros estudos que apontam a dificuldade nos serviços de saúde devido aos poucos atendimentos e número de profissionais insuficiente para atender a demanda dos usuários (Silva et al., 2017; Lopes et al., 2020).

Contudo, de acordo com os princípios do Sistema Único de Saúde (SUS) da regionalização e da hierarquização esse processo é algo esperado, que se relaciona com a realidade de cada município e seus polos de atendimento especializado. A regionalização e a hierarquização dispõem sobre os serviços de saúde que devem ser organizados em níveis crescentes de 
complexidade, circunscritos a uma determinada área geográfica, planejados a partir de critérios epidemiológicos, com definição e conhecimento da população a ser atendida (Brasil, 1990).

Em diversas ocasiões os profissionais de saúde necessitam fazer adaptações para que o atendimento da população seja realizado (Dantas et al., 2021). O limite de acesso aos serviços de saúde que as famílias encontram é uma situação de vulnerabilidade social, pensando que em muitos casos o atendimento não é vinculado a uma rede de saúde. Portanto, a família necessita realizar esse trajeto de forma independente, e caso não tenha recursos para isso, a criança pode ter seu estado de saúde agravado, podendo ficar sem o atendimento necessário.

Além disso, a demora em conseguir consulta com um especialista amplia a vulnerabilidade vivenciada pela família. Outra pesquisa também evidenciou a demora no atendimento, principalmente com especialistas e na realização de exames e, consequentemente, de resolução dos problemas de saúde em determinados serviços. Os usuários descreveram o acesso ao serviço primário à saúde, como sendo algo burocrático e demorado (Silva et al., 2020).

O médico pediatra proporciona segurança aos pais e aos demais profissionais de saúde que assistem à criança. No entanto, na Estratégia de Saúde da Família (ESF), os médicos são de formação clínica generalista. Esses não estão habilitados em todas as áreas de atenção médica, mas considera-se que o médico generalista também possa ter preparo para atender crianças (Rodrigues, 2017).

Para o diagnóstico da condição crônica da criança, as famílias relataram que utilizaram alguns espaços de saúde, como a Unidade Básica de Saúde, Hospital (para os que são de outros municípios), Consultas particulares, Planos com sindicatos para consulta médica, Pronto Socorro de Pelotas e os Hospitais com internação pediátrica do município de Pelotas. O uso de serviços de saúde variados reflete as dificuldades encontradas pelas famílias para conseguir o atendimento.

A fragmentação da rede de atenção à saúde traz descontinuidade de cuidados à família e à criança, fazendo com que haja uma peregrinação em busca desses, ocasionando impactos negativos na qualidade de vida dos indivíduos. Constata-se que as famílias vivenciam situações de vulnerabilidade nas quatro dimensões apresentadas anteriormente. Entretanto, nesta situação, destaca-se a vulnerabilidade social, porque a família quer e não pode ofertar a atenção que a criança necessita, uma vez que os serviços de saúde não atendem as demandas de saúde da população.

Relembrando que as propostas da ESF são consolidar os princípios do SUS, entre eles o do acesso universal, o acesso deveria ser facilitado, assim sendo, ao procurar o serviço a pessoa teria resolutividade (Ayres, 2009), a resolutividade não compreende, exclusivamente, a cura de doenças, mas também, o alívio ou a minimização do sofrimento, a promoção e a manutenção da saúde (Costa et al., 2014).

Nesse sentido, identifica-se que as lacunas no atendimento à criança com condição crônica iniciam-se com o planejamento dos programas e das políticas públicas que norteiam a rede de serviços de saúde, levando a situações de vulnerabilidade, com prejuízos na organização e na qualidade dos serviços ofertados. Diante dessa realidade de saúde, há a sobrecarga para a família (Vaz, Milbrath \& Gabatz). Portanto, é necessário identificar as crianças com condição crônica e monitorar seu atendimento, garantindo assim a acessibilidade e a articulação universal adequada nos diferentes níveis de atenção, buscando, assim, melhorar a promoção, proteção da saúde, rumando para uma sociedade mais justa (Hall et al., 2019; Santos et al., 2018).

É necessário considerar que para os profissionais de saúde também possuem dificuldades em aceitar que a criança possui uma condição crônica. Sendo assim, pode ser dificultado o diagnóstico correto. Estudo aponta a dificuldade em detectar precocemente o diagnóstico da criança, compreendendo-se isso como sendo uma falha do serviço de saúde (Matoso, Oliveira \& Costa, 2014).

Nesse sentido, e considerando que os serviços de saúde são os espaços onde essas famílias e crianças procuram atendimento, diagnóstico e tratamento para a condição crônica, e que esses espaços não conseguem suprir suas necessidades 
em saúde, amplificam-se as situações de vulnerabilidade social dessas famílias, pois as práticas coletivas de enfrentamento e as adversidades, como a disponibilidade de recursos e acesso a esses são componentes sociais.

Nesse contexto, a vulnerabilidade social da família encontra-se interligada diretamente com precária estrutura dos serviços de saúde e com o despreparo dos profissionais para o atendimento da criança cronicamente enferma.

\section{Considerações Finais}

O estudo possibilitou conhecer as situações de vulnerabilidade vivenciadas pelos familiares/cuidadores na recepção do diagnóstico da condição crônica da criança. Apresentando a peregrinação das famílias para receber o diagnóstico da condição crônica da criança. Sendo assim, é imprescindível à constituição de redes de serviço ao atendimento a crianças e famílias, objetivando atender às necessidades da família, bem como respeitando e acolhendo a criança com condição crônica na sua singularidade. Destaca-se que a elaboração de um modelo de atenção às famílias e crianças com condição crônica tem como premissa a participação da criança, da família e dos profissionais de saúde e educação, que discutam juntos as opções para um melhor cuidado, pois acredita-se que deste modo será possível criar um plano de cuidados dinâmico e que atenda às necessidades. Assim, minimizando as situações de vulnerabilidade, fortalecendo e empoderando a família e a criança com condição crônica.

Como limitações do estudo aponta-se o fato de ter entrevistado, em sua maioria, apenas um membro da família. Ainda, algumas entrevistas necessitaram ser realizadas no local de trabalho do participante ou no serviço de saúde utilizado pela família, o que pode interferir. Somado a isso teve-se dificuldade em localizar algumas famílias, devido ao fato de residirem em outros municípios, no interior sem indicação precisa de endereço.

O estudo traz contribuições para o ensino no sentido de qualificar a formação do enfermeiro, abordando e discutindo, na perspectiva da integralidade, o tema do cuidado à saúde da família e da criança com condição crônica. Para a assistência aponta-se a necessidade de olhar para as famílias/cuidadores das crianças com condição crônica, visando proporcionar que essas identifiquem as situações de vulnerabilidade (ontológica, ética, social e cultural) que vivenciam, incentivando-as a enfrentar essas situações enquanto cidadãos, e proporcionando melhor qualidade de vida dessas famílias e crianças. Além disso, pretende-se instigar a reflexão para repensar o modelo de atenção a essas famílias, compreendendo, assim, as suas necessidades e as da criança.

\section{Conflito de interesses}

Os autores declaram não ter nenhum conflito de interesse.

\section{Referências}

Ataide, C. A. \& Ricas, J. (2017). O enfrentamento do diagnóstico da doença falciforme: Desafios e perspectivas vivenciadas pela família. Scientia Plena, 13(5), 059908. https://doi.org/10.14808/sci.plena.2017.059908

Ayres, J. R. C. M. (2009). Organização das ações de atenção à saúde: modelos e práticas. Revista Saúde e Sociedade, 18, Suppl. 2, 11-23. https://doi.org/10.1590/S0104-12902009000600003

Brasil. Ministério da Saúde. Conselho Nacional de Saúde. Resolução CNS nº 466, de 12 de dezembro de 2012: diretrizes e normas regulamentadoras de pesquisas envolvendo seres humanos.

Brasil. Ministério da Saúde. Lei $n^{\circ}$ 8080, de 19 de setembro de 1990.Dispõe sobre as condições para a promoção, proteção e recuperação da saúde, a organização e o funcionamento dos serviços correspondentes e dá outras providências. Brasília: Ministério da Saúde; 1990.

Braun V, Clarke V, Hayfield N, Terry G. Thematic Analysis. In: Liamputtong P (edit.). Handbook of Research in Health Social Sciences. Australia: Springer, 2019. p. $843-60$

Brotto, A. L. \& Guimarães, A. B. P. (2017). A influência da família no tratamento de pacientes com doenças crônicas. Revista Psicologia Hospitalar, 15(1), 43-68. Available from: http://pepsic.bvsalud.org/pdf/ph/v15n1/15n1a04.pdf 
Cardoso, E. L. S., Santos, S. R., Araújo, Y. B., Neves, N. T. A. T., Nascimento, J. A. (2021). Fatores associados à qualidade de vida de cuidadores de crianças e adolescentes com condições crônicas. Revista Gaúcha de Enfermagem, 42, e20190318. https://doi.org/10.1590/1983-1447.2021.20190318

Collins, A., Hennessy-Anderson, N., Hosking, S., Hynson, J., Remedios, C. \& Thomas, K. (2016). Lived experiences of parents caring for a child with a lifelimiting condition in Australia: a qualitative study. Journal palliative medicine, 30(10), 950-959. https://doi.org/10.1177 / 0269216316634245

Costa, J. P., Jorge, M. S. B., Vasconcelos, M. G. F., Paula, M. L. \& Bezerra, I. C. (2014). Resolubilidade do cuidado na atenção primária: articulação multiprofissional e rede de serviços. Saúde e debate, 38(103), 733-743. https://doi.org/10.5935/0103-1104.20140067

Dantas, M. N. P., Souza, D. L. B., Souza, A. M. G., Aiquoc, K. M., Souza, T. A. \& Barbosa, I. R. (2021). Factors associated with poor access to health services in Brazil. Revista brasileira de Epidemiologia, 24, e210004. https://doi.org/10.1590/1980-549720210004

Dominguez, A. G. D. \& Castro, N. C. (2015). Doença crônica na infância: desafios para a promoção de saúde e redes sociais de apoio. Revista Eletrônica de Relações Internacionais do Centro Universitário Unieuro, 15, 117-150. http://www.unieuro.edu.br/sitenovo/revistas/Aldira\% 20Guimar\%C3\%A3es\%20Duarte\%20e\%20Nadia\%20Castro\%20(6).pdf

Favaro, L. C., et al. (2020). Percepção do enfermeiro sobre assistência às crianças com necessidades especiais de saúde na atenção primária. REME Revista Mineira de enfermagem, 24, e-1277. https://doi.org/10.5935/1415-2762.20200006

Freitag, V. L., Milbrath, V. M. \& Motta, M. G. C. (2016). Mãe-cuidadora de criança/adolescente com Paralisia Cerebral: o cuidar de si. Enfermería global, 50, 337-348. http://dx.doi.org/10.6018/eglobal.17.2.265821

Frizzo, N. S., Quintana, A. M., Salvagni, A., Barbieri, A. \& Gebert, L. (2015). Significações dadas pelos progenitores acerca doo diagnóstico de câncer dos filhos. Revista Psicologia: Ciência e Profissão, 35(3), 959-972. http://dx.doi.org/10.1590/1982-3703001772013

Frota, M. A. et al. (2017). Compreensão da criança acerca do câncer. Atas CIAIQ, 2, 1672-1677. https://proceedings.ciai q.org/index.php/ciaiq2017/article/view/1608

Hennink, M. M., Kaiser, B. K. \& Marconi, V. C. (2017). Code Saturation Versus Meaning Saturation: How Many Interviews Are Enough? Qualitative Health

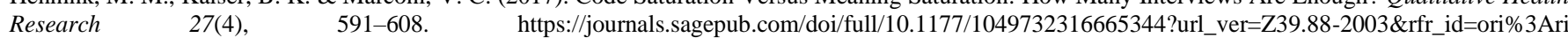
d\%3Acrossref.org\&rfr_dat=cr_pub\%3Dpubmed.

Hall, C. A., Donza, C., McGinn, S., Rimmer, A., Skomial, S., Todd, E. \& Vaccaro, F. (2019). Health-Related Quality of Life in Children with Chronic Illness Compared to Parents: A Systematic Review. Systematic Review, 31(4), 315-322. http://dx.doi.org/10.1097/PEP.0000000000000638

Lise, F., Schwartz, E., Milbrath, V. M., Santos, B. P., Feijó, A. M. \& Garcia, R. P. (2017) Children in conservative renal treatment: experiences of family caregivers. Texto \& contexto enfermagem, 26(3), e1110016. http://dx.doi.org/10.1590/0104-07072017001110016

Lopes, A. C. C., Nóbrega, V. M., Santos, M. M., Batista, A. F. M. B., Ramalho, E. L. R. \& Collet, N. (2020). Healthcare to youth with chronic illness. REFACS Revista Família, Ciclos de vida e saúde no contexto social, 8, Supl. 2. http://dx.doi.org/10.18554/refacs.v8i0.4286

Matoso, L. M. L., Oliveira, L. E. C. \& Costa, S. L. (2014). Uma proposta de identificação do câncer infanto-juvenil a partir da atenção básica. Revista Ciência e Desenvolvimento, 7(2), 187-205. http://srv02.fainor.com.br/revista/index.php/memorias/article/view/311/205

Milbrath, V. M. et al. (2016). Direitos das crianças com necessidades especiais: situações de vulnerabilidade das famílias. Journal of Nursing and Health, 6(1), 27-37. http://doi.dx.org/10.15210/JONAH.V6I1.4872

Pimenta, E. A. G., Wanderley, L. S. L., Soares, C. C. D. \& Delmiro, A. R. C. A, (2020). Cuidar de crianças com necessidades especiais de saúde: Do diagnóstico às demandas de cuidados no domicílio. Brazilian Journal of Development, 6(8), 58506-521. http://doi.dx.org/10.34117/bjdv6n8-311

Pimentel R. S., Targa, T. \& Scardoelli, M. G. C. (2017). Do diagnóstico ao desconhecido: percepções dos pais de crianças e adolescentes com diabetes mellitus. Revista de enfermagem UFPE on line, 11(3), 1118-26. http://doi.dx.org/10.5205/reuol.10544-93905-1-RV.1103201701

Rodrigues, D. C. (2017). Acesso de crianças com condição crônica na atenção primária em saúde: percepções de profissionais. Dissertação (Mestrado em Enfermagem). Universidade Federal de Santa Maria. https://repositorio.ufsm.br/bitstream/handle/1/12817/DIS_PPGENFER MAGEM_2017_RODRIGUES_DAISY.pdf?sequence=1\&isAllowed=y

Roselló, F. T. (2009). Antropologia do Cuidar. Vozes.

Santos, M. R., Souza, T. C. S. M, Misko, M. D., Silva, L. \& Szylit, R. (2018). Integrando a teoria do cuidado humano à prática de enfermeiros com famílias de crianças internadas. Revista saúde, 12 (1-2), 15-23. http://doi.dx.org/10.33947/1982-3282-v12n1-2-3302

Silva, C. R., Carvalho, B. G., Cordoni-Júnior, L. \& Nunes, E. F. P. A. (2017). Difficulties in accessing services that are of medium complexity in small municipalities: a case study. Ciência e Saúde Coletiva, 22(4), 1109-1120. http://doi.dx.org/10.1590/1413-81232017224.27002016

Silva, L. S., Viegas, S. M. F., Nascimento, L. C., Menezes, C., Martins, J. R. T. \& Potrich, T. (2020). Universalidade do acesso e acessibilidade no quotidiano da atenção primária: vivências de usuários do SUS. Revista de Enfermagem do Centro-Oeste Mineiro, 10, e3575. http//doi.org/10.19175/recomv10i0.3575

Tong, A., Sainsbury, P. \& Craig, J. (2007). Consolidated criteria for reporting qualitative research (COREQ): a 32-item checklist for interviews and focus groups. International Journal for Quality in Health Care, 19(6), 349-357. http://doi.dx.org/10.1093/intqhc/mzm042

Vaz, J. C., Milbrath, V. M. \& Gabatz, R. I. B. (2019). Conhecendo as crianças com condição crônica e suas famílias. Atas - Investigação Qualitativa em Saúde, 2,313-22. https://proceedings.ciaiq.org/index.php/CIAIQ2019/article/view/2033/1969

Wolkers, P. C. B., Pina, J. C., Wernet, M., Furtado, M. C. C. \& Mello, D. F. (2019). Children with diabetes mellitus type 1: vulnerability, care and access to health. Texto \& contexto enfermagem, 28, e20160566. http://doi.dx.org/10.1590/1980-265x-tce-2016-0566

Xavier, D. M., Gomes, G. C. \& Cezar-Vaz, M. G. (2020). Meanings assigned by families about children's chronic disease diagnosis. Revista Brasileira de Enfermagem, 73(2), e20180742. http://dx.doi.org/10.1590/0034-7167-2018-0742 